giai đoạn muộn, tuy nhiên với viêm gan $C$ thì chưa có nhiều nghiên cứu trong nước. Trong nghiên cứu của chúng tôi, nồng độ trung bình của một trong ba chỉ số AFP, AFP-L3\% và PIVKA-II có giá trị tăng cao vượt ngưỡng cut off ở nhóm bệnh nhân có khối u là $87,5 \%$, và ngược lại trong nhóm bệnh nhân không có u thì cả ba chỉ số này đều dưới ngưỡng cut off là $22 \%$. Kết quả này tương tự như nghiên cứu trên thế giới, khi họ xem bộ ba AFP, AFP-L3\% và PIVKA-II là chỉ dấu chẩn đoán sớm ung thư ở các bệnh nhân viêm gan $C$ virus [9].

\section{KẾT LUÂN}

Qua nghiên cứu trên 33 bệnh nhân viêm gan C tại Trung tâm $\mathrm{Y}$ học hạt nhân và Ung bướu, Bệnh viện Bạch Mai từ tháng 10/2019 đến tháng 3/2021. Cho thấy:

- Bệnh nhân nam giới chiếm đa số là 66,7\%, nữ giới chiếm tỷ lệ là $33,3 \%$, tỷ lệ nữ/nam là $2 / 1$, tuổi trung bình cả nam và nữ là 53,7 tuổi, trẻ nhất là 26 tuổi, già nhất là 83 tuổi.

- Nghiện rượu là đặc điểm có tỷ lệ cao nhất $39,4 \%$, xở gan kết hợp viêm gan $B$ có tỷ lệ thấp nhất $6,1 \%$.

- Các triệu chứng lâm sàng thường gặp là chán ăn, mệt mỏi, chướng bụng. Các triệu chứng lâm sàng ít gặp là buồn nôn, gan to, lách to.

- Các chỉ số cao hơn giá trị người bình thường là AST 173,5 $\pm 449 \mathrm{U} / \mathrm{L}, \mathrm{ALT} 121,8 \pm 258,4 \mathrm{U} / \mathrm{L}$, tải lượng HCV-RNA là $2 \times 10^{6} \pm 2,4 \times 10^{6} \mathrm{cp} / \mathrm{mL}$.

- Nhóm bệnh nhân có u, một trong ba chỉ số AFP, AFP-L3\% và PIVKA-II vượt ngưỡng có tỷ lệ là 87,5\%, trong nhóm bệnh nhân không có u, cả ba chỉ số dưới ngưỡng là $22,2 \%$

\section{TÀI LIÊU THAM KHẢO}

1. The Washington manual of medical therapeutics 33nd edition. Hyuna Sung PhD Jacques Ferlay MSc, M.R.L.S.M.M.L.M.I.S.M., et al (2021) Global cancer statistics 2020: GLOBOCAN estimates of incidence and mortality worldwide for 36 cancers in 185 countries. CA: a cancer journal for clinicians. U'HO

2. Lefkowitch, J.H. (2007). Liver Biopsy Assessment in Chronic Hepatitis. Archives of Medical Research. 38(6), 634-643.

3. Rockey, D.C., Caldwell S.H., Goodman Z.D., et al. (2009). Liver biopsy. Hepatology. 49(3), 1017-44

4. Ricco G et al. (2018). Impact of etiology of chronic liver disease on hepatocellular carcinoma biomarkers. Cancer Biomark; 21(3):603-612

5. Lim T.S., D.Y. Kim, K.-H. Han, et al (2016). Combined use of AFP, PIVKA-II, and AFP-L3 as tumor markers enhances diagnostic accuracy for hepatocellular carcinoma in cirrhotic patients. Scandinavian journal of gastroenterology, 51(3), 344-353.

6. Hann H.-W., D. Li, H. Yamada, et al (2014), Usefulness of highly sensitive AFP-L3 and DCP in surveillance for hepatocellular carcinoma in patients with a normal Alpha-Fetoprotein. J Med Microb Diagn, 3(1), 1-6.

7. Ngô Thi Thanh Quýt, Nguyễn Phương, Lê Thành Lý, Bùi Hữu Hoàng (2010), "Chẩn đoán mức đô xơ hóa gan bằng phương pháp đo độ đàn hồi gan trên bệnh nhân bệnh gan mạn", Tap chí Y Hoc Thành phổ Hồ Chí Minh, 14(1), tr.161-166.

8. Lẩm Hoàng Cát Tiên (2005), Khảo sát giá trị của phương pháp chẩn đoán khống xâm lấn trong xơ gan còn bù, Luân văn bác sĩ nội trú, Đại học Y Dược TP.Hồ Chí Minh.

9. Ivan G, Antonio B, Riccardo S. Diagnostic Accuracy of PIVKA-II, Alpha-Fetoprotein and a Combination of both in Diagnosis of Hepatocellular Carcinoma in Patients Affected by Chronic HCV Infection. In Vivo July 2017, 31 (4) 695-700

\title{
TÌNH TRANG DINH DƯỡ'NG VÀ ĐẶC ĐIỂM THÀNH PHẦN CƠ THỂ CỦA PHỤ NỮ 15 - 35 TUỔI TẠI HUYÊ̂N MƯỜNG LA, TỈNH SƠN LA NĂM 2018
}

\author{
Nguyễn Thúy Anh ${ }^{1}$, Nguyễn Song Tú ${ }^{1}$, \\ Nguyễn Hồng Trường ${ }^{1}$, Hoàng Nguyễn Phương Linh ${ }^{1}$
}

\section{TÓM TẮT}

Nghiên cứu được thực hiện nhằm đánh giá tình trang dinh dưỡng (TTDD) và đăc điểm thành phần cơ thể của phu nữ từ 15 đến 35 tuổi tại 5 xã nghèo của huyện Mường La, tỉnh Sơn La. Kết quả nghiên cứu cho

${ }^{1}$ Viện Dinh dưỡng Quốc gia

Chịu trách nhiệm chính: Nguyễn Thúy Anh Email: nguyenthuyanh@dinhduong.org.vn Ngày nhận bài: 6.8.2021

Ngày phản biên khoa hoc: 1.10 .2021

Ngày duyệt bài: 11.10.2021 thây cân nặng trung bình là 48,5 $\pm 6,5 \mathrm{~kg}$, chiêu cao trung bình là $151,8 \pm 5,3 \mathrm{~cm}$ và chỉ số khối cơ thể (BMI) trung bình là $21,0 \pm 2,4 \mathrm{~kg} / \mathrm{m}^{2}$. Tỷ lệ thiếu năng lượng trường diễn (CED) nhóm 20-35 tuổi là 8,9\% trong đó tỷ lệ SDD thấp còi và gâyy còm ở nhóm 15-19 tuổi lần lướt là $40 \%$ và $5,6 \%$. Cân năng, chiều cao và BMI trung bình giữa 4 nhóm tuổi của ĐTNC có sư khác biệt có YNTK $(p<0,001)$. Phần trăm mõ cơ thể $(\% B F)$ và khối lương mõ (FM) ở ĐTNC có sư thay đổi tăng dần theo lớp tuổi tăng dần, chỉ số \%BF và FM ở ĐTNC giữa các nhóm 15-19 và 30-35 khác biêt có YNTK vớl các nhóm tuổi còn lại $(p<0,05)$. Khối lượng cơ ước tính (PMM), khối lượng không mơ (FFM) ở ĐTNC cũng 
tăng dân theo nhóm tuổi tăng dân. PMM và FFM ở ĐTNC nhóm tuổi 15 - 19 khác biệt có YNTK với 3 nhóm tuổi còn lại $(p<0,05)$. Trong nghiên cứu này, mặc dù tỷ lệ CED của ĐTNC không cao nhưng tỷ lệ phụ nữ có cẩn nặng thấp (dưới $45 \mathrm{~kg}$ ) khá cao, chiếm $27,8 \%$. Do vậy can thiệ̃p cải thiện tình trang dinh dưỡng cho PNTṠĐ tại các xã̃ nghèo nơi đây là rất cần thiết.

Tư khóa: tình trang dinh dưỡng, thiếu năng lượng trường diễn, đặc điểm thành phân cơ thể, phụ nữ tuổi sinh đẻ.

\section{SUMMARY \\ BODY COMPOSITION AND NUTRITIONAL STATUS OF WOMEN AGED 15-35 YEARS OLD OF FIVE POOR COMMUNES IN MUONG LA DISTRICT, SON LA PROVINCE, 2018}

The study was carried out to assess the nutritional status and body composition characteristics of women aged 15-35 years old in 5 poor communes of Muong La district, Son La province. The study results showed that the average weight was $48.5 \pm 6.5 \mathrm{~kg}, 27.8 \%$ of women with low weight (under $45 \mathrm{~kg}$ ). The average height was $151.8 \pm 5.3 \mathrm{~cm}$ and average BMI was 21.0 $\pm 2.4 \mathrm{~kg} / \mathrm{m} 2$. The prevalence of CED in the age group of $20-35$ was $8.9 \%$, the prevalence of stunting and wasting in the $15-19$ age group are $40 \%$ and $5.6 \%$, respectively. The average weight, height and BMI among the 4 age groups were significantly different ( $p$ $<0.001)$. The percentage of body fat (\%BF) and fat mass (FM) of the subjects increased gradually with increasing age group, \%BF and FM were significantly different between the groups of 15-19 years old and $30-35$ years old with remaining age groups $(p<0.05)$. Muscle mass (PMM), fat-free mass (FFM) of the subjects also increased gradually with increasing age group. PMM and FFM of the subjects in the 15-19 age group were significantly different with the other 3 age groups $(p<0.05)$. In this study, although the prevalence of CED of the subjects was not high, the proportion of women with low weight (under $45 \mathrm{~kg}$ ) was quite high, accounting for $27.8 \%$. Therefore, intervention to improve the nutritional status of women in poor communes here is very necessary.

Keywords: nutritional status, chronic energy deficiency, body composition, women of reproductive age

\section{I. ĐẶT VẤN ĐỀ}

Thiếu năng lượng trường diễn ở PNTSĐ là một vấn đề sức khỏe cộng đồng, phổ biến ở các nước đang phát triển, đặc biệt là ở Châu Á và Châu Phi. TTDD và sức khỏe của bà me nói chung và phụ nữ tuổi sinh đẻ nói riêng có ảnh hưởng lớn đển sự tăng trưởng và phát triển của trẻ. Nhiều nghiên cứu ghi nhận rằng TTDD của mẹ khi có thai là yếu tố quyết định đối với sự phát triển của thai nhi, cân nặng, chiều dài của trẻ sơ sinh và TTDD của trẻ nhỏ. Nghiên cứu ở Ấn Độ hay Nigeria cho thấy những phụ nữ bị CED khi mang thai sẽ sinh ra những đứa trẻ có nguy cơ bị suy dinh dưỡng cao hơn $[1,2]$.

Trong những năm qua, ở Việt Nam, TTDD của những đối tượng có nguy cơ cao như trẻ em và PNTSE cũng được cải thiện. Theo kết quả Tổng điều qua dinh dưỡng toàn quốc 2009-2010 cho thấy tỷ lệ thiếu năng lượng trường diễn của phụ nữ khá cao, năm 2000 là 28,5\%, năm 2005 là $21,9 \%$ và đến năm 2009 , tỷ lệ này giảm xuống còn $18,0 \%$, tuy nhiên tốc độ giảm còn chậm. Đặc biệt, tỳ lệ CED của PNTSĐ dân tộc thiểu số ở miển núi phía Bắc những năm gần đây vẫn là vấn đề cần quan tâm. Một số điều tra cho thấy tỷ lệ CED ở PNTSĐ còn cao, tỷ lệ CED ở phụ nữ dần tộc thiểu số tại Tuyên Quang năm 2016 là 22,2\% [3], tại Thái Nguyên năm 2017 là 16,4\% [4].

Các chỉ số trong đánh giá TTDD của người trưởng thành đó là cân nặng, chiều cao, BMI, tình trạng dinh dưỡng và các chỉ số liên quan đến thành phần cơ thể. Ở Việt Nam có rất ít các nghiên cứu đánh giá đặc điểm thành phần cơ thể trên PNTSĐ nhất là phụ nữ ở các khu vực miền núi phía Bắc. Và đây là một trong những vấn đề mới cần quan tâm và nghiển cứu. Qua đó, có thể thấy nghiên cứu này là cần thiết, được tiến hành với mục đích nhằm đánh giá đặc điểm thành phần cơ thể và TTDD của phụ nữ từ 15 - 35 tuổi tại huyện Mường La, tỉnh Sơn La.

\section{II. ĐỐI TƯợNG VÀ PHƯƠNG PHÁP NGHIÊN CỨU}

2.1 Tiểu chuẩn lựa chọn đối tượng, địa điểm và thời gian nghiên cứu:

Đối tượng đáp ứng các tiêu chí:

- Phụ nữ trong độ tuổi 15-35, không có thai; không có dị tật bẩm sinh về hình thể.

- Chấp thuận tham gia nghiên cứu.

Địa điểm và thời gian: tại 5 xã của huyện Mường La, tỉnh Sơn La trong thời gian từ tháng 07/2018 đến tháng 12/2018.

\subsection{Thiết kế nghiên cứu: Mô tả cắt ngang}

2.3. Cỡ mẫu: Áp dụng công thức tính cỡ mẫu:

$$
\frac{Z^{2}(1-a / 2) \cdot p(1-p) \times D E}{d^{2}}
$$

$\mathrm{n}=$

Trong đó: $\mathrm{n}$ là số đối tượng cần điều tra; $\mathrm{p}$ là tỷ lệ CED ở PNTSĐ, năm 2014 là $15,1 \%$ [5]; d là khoảng sai lệch chấp nhận. Chọn $d=0,05 ; Z$ giá trị thu được từ bảng $z$, ứng với hệ số tin cậy $95 \%$ thì $Z_{(1-\alpha / 2}$ là 1,96; DE (Design effect) $=2$; Cỡ mẫu cần điều tra về tỳ lệ CED là 400 đối tượng. Thực tế điều tra 395 đối tượng.

\subsection{Phương pháp chọn mấu:}

Chọn tỉnh: Chọn chủ đích huyện Mường La, tỉnh Sơn.

Chọn xã: Chọn ngẫu nhiên đơn 5 xã trong 9 xã thuộc xã nghèo (là xã Chiềng Lao, Nậm Giôn, Mường Trai, Hua Trai, Ngọc Chiến) 
Chọn đối tượng nghiên cứu (ĐTNC): theo phương pháp ngấu nhiên hệ thống

\subsection{Phương pháp và công cụ thu thập} số liệu

+ Phỏng vấn: sử dụng bộ câu hỏi thu thập thông tin chung được thử nghiệm trước khi điều tra.

+ Cân đo nhân trắc: cân điện tử TANITA SC 330 với độ chính xác $0,1 \mathrm{~kg}$, có chức năng tư tính toán các thông số phần trăm mõ̃ cơ thể, khối mõ, khối lượng cơ ước tính, khối không mỡ. Dụng cụ đo chiều cao: sử dụng thước gỗ 3 mảnh có độ chính xác tới $1 \mathrm{~mm}$.

2.6. Một số tiêu chuẩn xác định, đánh giá

Đánh giá tình trạng dinh dưỡng của phụ nữ từ 15-19 tuổi: Dưa vào quần thể tham khảo của Tổ chức Y tế thế giới 2006 như sau:

Đánh giá chỉ số Z-score chiều cao theo tuổi: Z-score $<-2$ là SDD thể thấp còi; Z-score $\geq-2$ là bình thường; Đánh giá chỉ số Z-score BMI theo tuổi: Z-score < -2 là SDD thể gầy còm và $-2 \leq$ Z-score $\leq 1$ là bình thường

Chỉ số khối cơ thể (BMI): BMI được tính bằng tỷ số giữa cân nặng cơ thể tính bằng kilôgam $(\mathrm{kg})$ với chiều cao bình phương tính bằng mét $(\mathrm{m})$.

Phân loại tình trạng dinh dưỡng của người trưởng thành $20-69$ tuổi theo khuyến nghị của TCYTTG năm 2000 là: CED độ II (gây độ II) khi BMI từ 16,0 đến 16,99; Gầy độ I (CED độ I) khi BMI từ 17 - 18,49;
Để đánh giá mức độ CED trên quần thể, Tổ chức $Y$ tế Thế giới cũng đã đưa ra ngưỡng đánh giá về mặt YNSKCD như sau: Mức độ nhe khi CED 5-9\%; Mức độ trung bình khi CED 10-19\%;

2.7. Phân tích và xử lý số liệu: Sử dụng phần mềm Epi Data 3.1 để nhập liệu và SPSS 18.0 để phân tích. Test kiểm định thống kê là $\chi^{2}$ test để so sánh 2 tỷ lệ, $\mathrm{t}$ - test độc lập so sánh giá trị trung bình 2 nhóm, ANOVA test so sánh giá trị trung bình của 3 nhóm Giá trị $p<0,05$ được xem có ý nghĩa thống kê (YNTK).

2.8. Đạo đức nghiên cứu: Nghiên cứu đã được chấp thuận bởi Hội đồng đạo đức của Viện Dinh dưỡng trước khi triển khai, theo quyết định số 1474 /QĐ-VDD ngày 14/09/2018.

\section{KẾT QUẢ NGHIÊN CỨU}

Nghiên cứu đã tiến hành trên 395 phụ nữ 1535 tuổi tại 5 xã thuộc huyện Mường La, tỉnh Sơn La; thuộc huyện nghèo của tỉnh miền núi phía Bắc có $79,5 \%$ ĐTNC là người Thái, $12,4 \%$ dân tộc $\mathrm{H}^{\prime}$ ông; còn lại $8,1 \%$ là các dân tộc khác bao gồm cả dân tộc Kinh. Tuổi trung bình của đối tượng là $25,6 \pm 6,7$; Kinh tế hộ gia đình $47,8 \%$ là hộ nghèo và 19,2\% là cận nghèo; còn lại 32,9\% bình thường; Nông nghiệp vẩn là nghề nghiệp đem lại thu nhập chính cho các gia đình $81,0 \%$, bên cạnh đó có $16,5 \%$ đối tượng là học sinh.

Bảng 1. Các chỉ số nhân trắc chính của đối tượng nghiên cứu

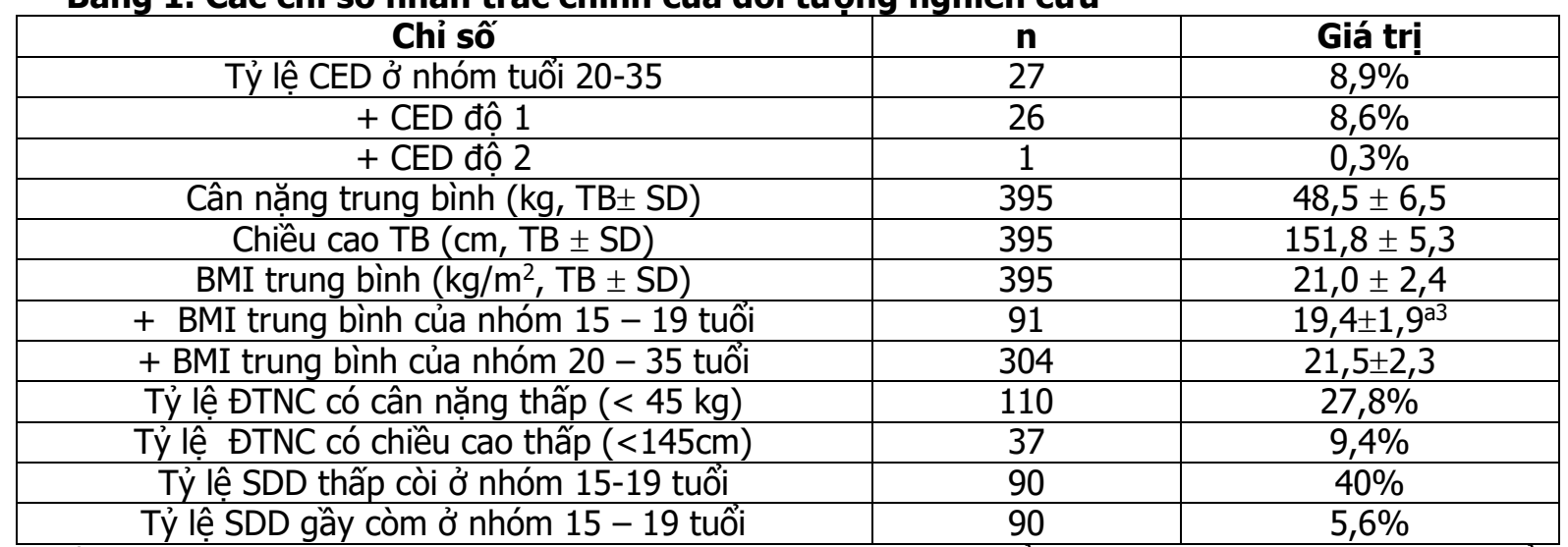

a) t-test ${ }^{1} \mathrm{p}<0,05,{ }^{2} \mathrm{p}<0,01,{ }^{3} \mathrm{p}<0,001$, so sánh giữa 2 nhóm tuối TB: trung bình; SD: độ lệch chuấn

Tỷ lệ phụ nữ CED ở 20-35 tuổi (CED) là 8,9\%; chủ yếu là CED độ $1(8,6 \%)$. Cân nặng trung bình (TB) của ĐTंNC là 48,5 $\pm 6,5 \mathrm{~kg}$. Chiêuu cao TB là $151,8 \pm 5,3 \mathrm{~cm}$; Tỷ lệ đối tượng có cân nặng thấp dưới $45 \mathrm{~kg}$ là $27,8 \%$ và chiếu cao thấp dưới $145 \mathrm{~cm}$ là $9,4 \%$. BMI trung bình của đối tượng là $21,0 \pm$ $2,4 \mathrm{~kg} / \mathrm{m}^{2}$, nhóm tuổi $15-19$ là $19,5 \pm 1,9 \mathrm{~kg} / \mathrm{m}^{2}$ và nhóm $20-35$ là $21,5 \pm 2,3 \mathrm{~kg} / \mathrm{m}^{2}$, sự khác biệt có YNTK về BMI giữa 2 nhóm tuổi (t-test, $\mathrm{p}<0,001$ ).

Bảng 2. Đặc điểm nhân trắc của đối tượng nghiên cứu theo nhóm tuổi

\begin{tabular}{|c|c|c|c|c|c|c|c|c|c|c|}
\hline \multirow{2}{*}{$\begin{array}{c}\text { Nhóm tuổi } \\
15-19 \text { tuổi }\end{array}$} & \multirow{2}{*}{$\frac{\mathbf{n}}{91}$} & \multicolumn{3}{|c|}{ Cân nặng (kg) ${ }^{\text {c3 }}$} & \multicolumn{3}{|c|}{ Chiêu cao $(\mathrm{cm})^{\mathrm{c} 3}$} & \multicolumn{3}{|c|}{ Chỉ số BMIc3 } \\
\hline & & 43,7 & \pm & 5,6 & 149,9 & \pm & 5,7 & 19,4 & \pm & 1,9 \\
\hline $20-24$ tuối & 69 & 48,3 & \pm & 5,2 & 152,6 & \pm & 4,9 & 20,7 & \pm & 2,0 \\
\hline
\end{tabular}




\begin{tabular}{|c|c|ccc|ccc|ccc|}
\hline $25-29$ tuối & 103 & 49,4 & \pm & 5,9 & 153,2 & \pm & 5,1 & 21,1 & \pm & 2,1 \\
\hline $30-35$ tuối & 132 & 51,1 & \pm & 6,5 & 151,6 & \pm & 5,1 & 22,2 & \pm & 2,4 \\
\hline Chung & 395 & 48,5 & \pm & 6,5 & 151,8 & \pm & 5,3 & 21,0 & \pm & 2,4 \\
\hline
\end{tabular}

TB: trung bình; SD: độ lệch chuấn; ${ }^{3)} p<0,001 \quad{ }^{c}$ ANOVA-test

Cân nặng, chiều cao và BMI trung bình ĐTNC khác biệt giữa các nhóm tuổi $(p<0,001)$; Cân nặng TB ĐTNC cao nhất là lớp tuổi 30-35 tuổi $(51,1 \mathrm{~kg})$ khác biệt có YNTK với 3 nhóm tuổi còn lại (post hoc test, $\mathrm{p}<0,05)$. Chỉ số BMI $(\mathrm{kg} / \mathrm{m} 2)$ của ĐTNC thấp nhất ở nhóm $15-19$ tuổi $(19,4 \mathrm{~kg} / \mathrm{m} 2)$ và tăng dần ở nhóm 30-35 tuổi $(22,2 \mathrm{~kg} / \mathrm{m2})$; có sự khác biệt có YNTK ở nhóm tuổi 15 - 19 và 30 - 35 với 3 nhóm tuổi còn lai (Post hoc test; $p<0,001$ ).

Bảng 3. Đặc điểm chỉ số phần trăm mỡ, khôi lượng mỡ của đối tượng nghiên cứu theo nhóm tuối

\begin{tabular}{|c|c|c|c|c|c|c|c|}
\hline Nhóm tuổi & $\mathbf{n}$ & \multicolumn{3}{|c|}{ Phân trăm mõ̃ (\%) ${ }^{c 3}$} & \multicolumn{3}{|c|}{ Khối lượng mõ̃ (kg) c3 } \\
\hline 15-19 tuổi & 91 & 24,8 & \pm & 4,7 & 11,1 & \pm & 3,2 \\
\hline 20-24 tuổi & 69 & 26,6 & \pm & 4,2 & 13,0 & \pm & 3,2 \\
\hline 25-29 tuổi & 103 & 27,4 & \pm & 4,1 & 13,7 & \pm & 3,6 \\
\hline 30-35 tuối & 132 & 29,6 & \pm & 4,4 & 15,4 & \pm & 4,1 \\
\hline Chung & 395 & 27,4 & \pm & 4,7 & 13,5 & \pm & 3,9 \\
\hline
\end{tabular}

TB \pm SD: trung bình; độ lệch chuấn; ${ }^{3)} p<0,001 \quad$ c) ANOVA-test

Phần trăm mỡ cơ thể (\%BF) và khối lượng mõ (FM) ở ĐTNC có sự thay đổi tăng dần theo lớp tuổi tăng dần $(\mathrm{p}<0,001)$; Chỉ số \%BF và $\mathrm{FM}$ ở ĐTNC giữa các nhóm 15-19 và 30-35 khác biệt có YNTK với các nhóm tuổi còn lại (post hoc test, $p<0,05$ ).

Bảng 4. Đặc điểm khối cơ và khối không mỡ của đôî tượng nghiên cứu theo nhóm tuổi

\begin{tabular}{|c|c|c|c|c|c|c|c|}
\hline Nhóm tuối & $\mathbf{n}$ & \multicolumn{3}{|c|}{ Khối lương cơ ước tính (\%) } & \multicolumn{3}{|c|}{ Khối lương không mỡ $(\mathbf{k g})^{c 3}$} \\
\hline 15-19 tuối & 91 & 30,9 & \pm & 2,8 & 32,7 & \pm & 3,0 \\
\hline 20-24 tuối & 69 & 33,3 & \pm & 2,3 & 35,3 & \pm & 2,6 \\
\hline 25-29 tuối & 103 & 33,7 & \pm & 2,6 & 35,7 & \pm & 2,9 \\
\hline 30-35 tuối & 132 & 33,8 & \pm & 2,8 & 35,7 & \pm & 3,1 \\
\hline Chung & 395 & 33,0 & \pm & 2,9 & 34,9 & \pm & 3,2 \\
\hline
\end{tabular}

TB: trung bình; SD: độ lệch chuấn; ${ }^{3)} \mathrm{p}<0,001{ }^{\mathrm{c})}$ ANOVA-test. Khối lượng cơ ước tính (PMM), khối lượng không mõ (FFM) ở ĐTNC tăng dần theo nhóm tuổi $(p<0,001)$. PMM và FFM ở ĐTNC nhóm tuổi 15 - 19 khác biệt có YNTK với 3 nhóm tuổi còn lại (post hoc test, $p<0,05$ ).

\section{BÀN LUẬN}

Kết quả cho thấy tỷ lệ CED của PNTSĐ từ 2035 tuổi ở huyện Mường La, tỉnh Sơn La không phải ở mức cao $(8,9 \%)$ trong đó tỷ lệ CED độ 1 chiếm phần lớn $8,6 \%$, tỷ lệ SDD thấp còi và gầy còm của lứa tuổi từ 15-19 tuổi lần lượt là là $40 \%$ và $5,6 \%$. Tỷ lệ CED thấp hơn đáng kể so với một số nghiên cứu trước đó như nghiên cứu ở PNTSĐ tại huyện Na Hang, tỉnh Tuyên Quang là 22,2\% [3] và tại huyện Phú Lương, tỉnh Thái Nguyên là 16,4\% [4]. Tuy nhiên, lại cao hơn so với kết quả nghiên cứu trên phụ nữ dân tộc H'Mông tại tỉnh Cao Bằng $(2,1 \%)[6]$, lý giải điều này bởi chiều cao TB của phụ nữ H'mông rất thấp, do đó dẫn đến có sự khác biệt lớn về tỷ lệ CED.

Cân nặng và chiêu cao TB của ĐTNC lần lượt là $48,5 \pm 6,5 \mathrm{~kg}$ và $151,8 \pm 5,3 \mathrm{~cm}$. So sánh cần nặng của PNTSĐ ở nghiên cứu này với một số nghiên cứu khác ở Thái Nguyên, Cao Bằng và Tuyên Quang là tương đương nhau. Nhưng, chiêu cao thì có sự khác nhau; chiêu cao TB của PNTSĐ ở Sơn La thấp hơn so với chiều cao TB của phụ nữ 24-29 tuổi trong Tổng điều tra Dinh dưỡng 2009-2010 $(153,4 \mathrm{~cm})$ và thấp hơn đáng kể so với chiều cao của PNTSĐ ở Tuyên Quang $(155,9 \pm 5,9 \mathrm{~cm})$ [3]. Thông qua các con số này, có thể lý giải tại sao tỷ lệ CED ở Sơn La không cao là do chiêu cao TB của PNTSĐ ở đây thấp hơn so với các nơi khác, trong khi không có sự khác biệt nhiều về cân nă̆ng. Vì vậy, chỉ số BMI của phụ nữ ở Sơn La nẳm trong giới hạn bình thường và tỷ lệ CED không cao.

Về cân nặng ở ĐTNC tăng dần theo các nhóm tuổi tăng dần; giữa 2 nhóm tuổi từ $15-19$ tuổi và 20 - 24 tuổi, cân nặng TB tăng đáng kể, nhưng từ 25 tuổi trở đi thì cân nặng TB có tăng nhưng tăng rất ít so với các nhóm tuổi trước đó. Mặc dù cân nă̆ng TB của ĐTNC cao hơn ngưỡng cân nặng thấp $(45 \mathrm{~kg})$ song tỷ lệ đối tượng có cân nặng thấp ở đây khá cao $(27,8 \%)$. Cũng tương tự như tỷ lệ tăng cân nặng giữa các nhóm tuổi, chiều cao TB tăng đáng kể trong khoảng từ $15-24$ tuổi $(2,7 \mathrm{~cm})$, từ $25-29$ tuổi tăng ít $(0,6 \mathrm{~cm})$. Chiều cao TB của nhóm đối tượng từ 30 -35 tuổi thấp hơn chiều cao TB của các nhóm 
20-24 tuổi và từ 25-29 tuổi, điều này có thể lý giải do nhóm phụ nữ trên 30 tuổi được sinh ra trong điều kiên hoàn cảnh kém đầy đủ hơn so với nhóm dưới 30 tuổi. Vì vâyy, có thể nói rằng với điều kiện kinh tế ngày càng phát triển thì chiều cao của người Việt Nam nói chung và PNTSĐ nói riêng ngày càng cải thiện. Với sự tăng dần về cân nặng và chiêu cao thì chỉ số BMI TB cũng tăng dần theo các nhóm tuổi tăng dần. Kết quả cho thấy chỉ số BMI TB của ĐTNC là $21 \pm$ $2,4 \mathrm{~kg} / \mathrm{m}^{2}$ và nằm trong ngưỡng bình thường.

Phân trăm mõ cơ thể (\%BF) và khối lượng mõ (FM) ở ĐTNC lần lượt là $27,4 \%$ và $13,5 \mathrm{~kg}$. Kết quả này thấp hơn so với kêt quả của nghiên cứu ở PNTSĐ dân tộc H'Mong tại huyện Bảo Lạc, tỉnh Cao Bằng $(28,8 \% ; 14,0 \mathrm{~kg})[6]$. So sánh với một số nghiên cứu ở các nước khác cho thấy phần trăm mõ cơ thể và khối lượng mõ của PNTSĐ ở Sơn La cũng thấp hơn nhiều. Kết quả nghiên cứu ở Saudi Arabia cho thây phần trăm mõ cơ thể ở phụ nữ từ 18-19 tuổi là 33,7\%, từ 20-29 tuổi là 36,3\%, từ 30-39 tuổi là 42,9\% [7]. Kết quả nghiên cứu ở Ba Lan cho thấy khối lượng mõ ở phụ nữ từ $20-29$ tuổi là $17,5 \mathrm{~kg}$, từ 30-39 tuổi là 21,0 kg [8]. Các kết quả về chỉ số $\% B F$ và $F M$ ở 2 nghiên cứu này cũng đều tăng dần theo độ tuổi. Qua một số các nghiên cứu, có thể thấy rằng $\mathrm{PNTS}$ ở Sơn La có tỷ lệ \% $\mathrm{BF}$ và FM thấp so với PNTSĐ ở cùng khu vực miền núi phía Bắc của Viêt Nam và thấp hơn nhiều so với PNTSĐ ở các nước khác trên thế giới $[6,7,8]$. Lý do là trong nghiên cứu này ĐTNC là phụ nữ thuộc 5 xã nghèo của huyện Mường La, tỉnh Sơn La với tỷ lệ hộ nghèo và cận nghèo chiếm hơn $60 \%$ và nghể nghiệp chủ yếu là làm nông nghiệp, nương rãy. Hơn nữa, các kết quả ở các nghiển cứu còn cho thấy, $\% \mathrm{BF}$ và $\mathrm{FM}$ ở phụ nữ thuộc các nhóm tuổi dưới 30 tuổi tăng ít hơn so với phụ nữ thuộc các nhóm tuổi trên 30 tuổi vì có thể do cơ thể của phụ nữ trên 30 tuổi dễ tích mõ hơn so với phụ nữ dưới 30 tuổi.

Khối lượng cơ ước tính (PMM) và khối lượng không mõ (FFM) ở ĐTNC tăng dần theo các nhóm tuổi tăng dần, có sự tăng đáng kể giữa nhóm tuổi $15-19$ và 20-24. Nhóm tuổi 25-29 và $30-35$ tăng rất ít hoặc không tăng. PMM và FFM trung bình của PNTSĐ ở nghiên cứu này là $33 \%$ và $34,9 \mathrm{~kg}$. PMM cao hơn so với PMM ở phụ nữ trong nghiên cứu tại Saudi Arabia (24,8\%) [7]. FFM thấp hơn so với kết quả của nghiên cứu ở Kenya $(38,9 \mathrm{~kg})$ [9] và nghiên cứu ở Ba Lan. Kết quả của nghiên cứu tại Ba Lan cho thấy FFM tăng dần theo các nhóm tuổi tăng dân, nhóm 20-29 tuổi là 44,2kg, nhóm 30-39 tuổi là 46,3kg, nhóm 40-49 tuổi là 47,5kg [8]. Qua các kết quả về thành phần cơ thể cho thấy phụ nữ càng nhiều tuổi thì tỷ lệ mõ cơ thể và khối lượng mõ càng tăng, tuy nhiên khối lượng cơ và khối lượng không mõ̃ thì tăng không đáng kể.

\section{KẾT LUẦN}

Kết quả nghiên cứu cho thấy cân nặng TB ở ĐTNC là $48,5 \pm 6,5 \mathrm{~kg}$, chiêu cao TB là $151,8 \pm$ $5,3 \mathrm{~cm}$ và $B M I$ TB là $21,0 \pm 2,4 \mathrm{~kg} / \mathrm{m}^{2}$. Tỷ lê CED của nhóm 20-35 tuổi là 8,9\% trong đó tỷ lệ SDD thấp còi và gây còm ở nhóm 15-19 tuổi lần lượt là $40 \%$ và $5,6 \%$. Cân năng, chiều cao và $B M I$ TB có sự khác biệt có YNTK giữa 4 nhóm tuổi. \%BF và $F M$ có sự thay đổi tăng dần theo lớp tuổi tăng dần, chỉ số \%BF và FM ở ĐTNC giữa các nhóm 15 -19 và 30-35 khác biệt có YNTK với các nhóm tuổi còn lại $(p<0,05)$. PMM, FFM ở ĐTNC cũng tăng dần theo nhóm tuổi tăng dần. PMM và FFM ở ĐTNC nhóm tuổi 15 - 19 khác biệt có YNTK với 3 nhóm tuổi còn lại $(p<0,05)$.

Lời cảm ơn: Nghiên cứu đã sử dụng kinh phí nghiên cứu khoa học của Viện Dinh dưỡng năm 2018.

\section{TÀI LIÊU THAM KHẢO}

1. Ravishankar Athimulam Kulasekaran (2012). Influence of mothers' chronic energy deficiency on the nutritional status of preschool children in Empowered Action Group states in India. International Journal of Nutrition, Pharmacology, Neurological Diseases; 2(3): 198-209

2. Idowu 0 Senbanjo, Ibiyemi 0 Olayiwola Wasiu A Afolabi et al (2013). Maternal and child under-nutrition in rural and urban communities of Lagos state, Nigeria: the relationship and risk factors. BMC research notes, 2013; 6:286

3. Chu Quỳnh Mai, Ninh Thi Nhung (2016). Nghiên cứu môtt số chỉ số nhẩn trắc của phu nữ lứa tuổi sinh đẻ dân tộc thiểu số tại huyên $\mathrm{Na}$ Hang tỉnh Tuyên Quang năm 2016. Tạp chí Dinh dưỡng \& Thực phẩm; 13(3): 7-12.

4. Trân Thị Hồng Vân, Lê Thị Hương (2017). Tình trang thiếu năng lượng trường diền và thiêu máu dinh dưỡng ở phụ nữ 20-35 tuổi người dân tộc Tày tại huyện Phú Lương, tỉnh Thái Nguyên năm 2017. Tạp chí Dinh dướng \& Thực phẩ; 15(1): 25-29.

5. Viện Dinh dưỡng, V.D., Thông tin giám sát dinh dưỡng.năm 2015. 2016.

6. Nguyê̂n Quang Dũng, Nguyễn Lân, Lê Danh Tuyên (2015). Tình trạng dinh dưỡng, đặc điểm thành phân cơ thể của phụ nữ tuổi sinh đẻ người H'Mông tại huyện Bảo Lạc, tỉnh Cao Bằng. Tạp chí Dinh dưỡng \& Thực phẩm; 11(4): 18-22.

7. Firas Sultan Azzeh, Hassan Mazzhar Bukhari, Eslam Ahmed Heade et al (2017). Trends in overweight or obesity and other anthropometric indices in adults aged 18-60 years in western Saudi Arabia. Ann Saudi Med, 2017 Mar-Apr; 37(2): 106-113. 
8. Pawel Wiech, Zdzislawa Chmiel, Dariusz Bazalinski et al (2021). Body Composition and Selected Nutritional Indicators in Healthy Adults-A Cross-Sectional Study. Glob Adv Health Med, 2021 Jun 3; Vol 10: 1-13.
9. Susan Keino, Bart van den Borne and Guy Plasqui (2014). Body composition, water turnover and physical activity among women in Narok County, Kenya. PMC Public Health, 2014 Nov 24; $14: 121$

\section{NHẬN XÉT GIÁ TRI CỦA PET/CT TRONG ĐÁNH GIÁ DI CĂN PHỔI Ở BÊ̂NH NHÂN UNG THƯ ĐẠI TRỰC TRÀNG}

\section{TÓM TẮT}

Mục tiêu: Nhân xét giá trị của PET/CT trong đánh giá di căn phổi ở bệnh nhân ung thư đại trực tràng đã điều trị. Đối tượng và phương pháp nghiên cứu: 39 bệnh nhân (18 bệnh nhân ung thư đại tràng và 21 bệnh nhân ung thư trực tràng) đã điều trị triệt căn có nốt tổn thương tại phổi được chụp CT cản quang và PET/CT (với ${ }^{18} \mathrm{~F}-\mathrm{FDEG}$ ) đánh giá tại bệnh viện Ung bướu Hà Nội từ tháng 10/2019 đến tháng 5/2020. Nghiên cứu mô tả cắt ngang, hồi cứu kết hợp tiến cứu. Kết quả: Tuổi trung bình của bệnh nhân trong nhóm nghiên cứu là $60,1 \pm 13,3$. 38, $5 \%$ số bệnh nhân có nồng độ CEA bình thường. PET/CT phát hiện số tổn thương dương tính nhiêuu hơn so với CT (48 so với 39). Đa số các trường hợp di căn phổi trong nhóm nghiên cứu có di căn nhiều nốt với kích thước nhỏ, giá trị SUVmax không cao. Kích thước trung bình các tổn thương tại phổi là $1,0 \pm 1,5 \mathrm{~cm}$. Giá trị SUVmax trung bình chung của cả nhóm nghiên cứu là 3,19 $\pm 2,23$. PET/CT có độ nhạy $(95,7 \%)$ và độ đăc hiệu $(62,5 \%)$ trong đánh giá các nốt tại phổi. Kết luận: PET/CT phát hiện nhiều tổn thương dương tính tại phổi hơn $\mathrm{CT}$ với đô nhay và độ đăc hiêu của chẩn đoán là $95,7 \%$ và $62,5 \%$. Tuy nhiệ̂n với giá trị dự báo dương tính cao, chi phí thấp và dễ thực hiện, $\mathrm{CT}$ vẫn hữu ích trong thực hành lâm sàng.

\section{SUMMARY}

TO REVIEW THE ROLE OF PET/CT IN THE EVALUATION OF LUNG METASTASES IN

THE COLORECTAL CANCER PATIENTS

Objective: To review the role of PET/CT in the evaluation of lung metastases in the colorectal cancer patients who had had undergone curative treatment. Material and methods: 39 patients (18 colon cancer and 21 rectal cancer) who had undergone curative treatment with pulmonary nodules were evaluated by contrast CT and PET/CT (with ${ }^{18} \mathrm{~F}-\mathrm{FDG}$ ) at Hanoi Oncology Hospital from October 2019 to May 2020. A

\footnotetext{
${ }^{1}$ Bệnh viện Ung bướu Hà Nội

2Trung tầm CĐHA và YHHN - bênh viên $K$

${ }^{3}$ Trường Đại họ Y Hà Nội, Trung tâm YHHN và UB Bênh viên Bach Mai

Chịu trách nhiệm chính: Nguyễn Văn Khải

Email: nguyen vankhai.ubhn@gmail.com

Ngày nhân bài: 5.8 .2021

Ngày phản biên khoa hoc: 4.10 .2021

Ngày duyệt bài: 14.10.2021
}

retrospective and prospective descriptive study. Results: The average age of patients in the study was $60,1 \pm 13,3$. 38,5\% of patients had normal CEA levels. PET/CT detected more positive lesions than CT (48 vs 39). Most of the cases of lung metastasis in the study group had metastases with many small nodules, SUVmax values were not high. The average size of pulmonary lesions was $1,0 \pm 1,5 \mathrm{~cm}$. The overall value of SUVmax of the group was 3,19 $\pm 2,23$. PET/CT has sensitivity $(95,7 \%)$ and specificity $(62,5 \%)$ in evaluating pulmonary nodules. Conclusion: PET/CT detected more positive pulmonary lesions than CT with diagnostic sensitivity and specificity of $95,7 \%$ and $62,5 \%$. However, with high positive predictive value, low cost and ease of implementation, CT remains useful in clinical practice.

Keywords: PET/CT, colorectal cancer, lung metastasis

\section{I. ĐẶT VẤN ĐỀ}

Ung thư đại trực tràng là một trong những loại ung thư có tỉ lệ mắc hàng đầu ở Việt Nam. Ngoài việc chẩn đoán, điều trị và đánh giá đáp ứng sau điều trị thì việc theo dõi phát hiện bệnh tái phát, di căn cũng có một vai trò quan trọng. Việc phát hiên sớm hay đánh giá đúng tổn thương có thể làm thay đổi chiến thuật, đưa ra các quyết định điêu trị phù hợp. UTĐTT di căn cơ quan xa phổ biến nhất đến phổi và tiếp sau là gan, tỉ lệ di căn phổi lên đến 15\% [1]. Với hình ảnh điển hình di căn phổi trên $C T$, việc chẩn đoán không quá khó khăn. Tuy nhiên, bệnh nhân UTĐTT được xác định có nốt ở đơn độc ở phổi trong trường hợp không có di căn khác là một tình trạng gây ra rất nhiều khó khăn cho bác sĩ lâm sàng trong việc phải đưa ra quyết định lựa chọn điều trị tiếp theo. Nhiều nghiên cứu đã được thực hiện so sánh khả năng của các kỹ thuât hình ảnh khác nhau để xác định đây đủ các đăc điểm của nốt đơn độc tại phổi là lành tính hay ác tính. Hiện nay hai kỹ thuật chính hiện được sử dụng để đánh giá là $\mathrm{CT}$ cán quang và $\mathrm{PET} / \mathrm{CT}$, vì vậy chúng tôi tiến hành nghiên cứu này nhằm mục tiêu nhận xét giá trị của $\mathrm{PET} / \mathrm{CT}$ trong đánh giá di căn phổi ở bệnh nhân ung thư đại trực tràng đã điều trị và so sánh với CT ngực có tiêm thuốc cản quang. 